\title{
Chronic bronchiolitis in a 5-yr-old child after exposure to sulphur mustard gas
}

\author{
E. Dompeling*, Q. Jöbsis*, N.M.A. Vandevijver", G. Wesseling ${ }^{\circledR}$, H. Hendriks*
}

Chronic bronchiolitis in a 5-yr-old child after exposure to sulphur mustard gas. E. Dompeling, Q. Jöbsis, N.M.A. Vandevijver, G. Wesseling, H. Hendriks. (CERS Journals Ltd 2004.

ABSTRACT: Exposure to sulphur mustard (SM) gas may have extensive immediate effects on the respiratory system. However, long-term effects are far less known. This case report describes a Kurdish male child who was exposed to SM gas during a chemical attack in Iraq at 5 yrs of age.

In the acute phase, the child developed severe respiratory symptoms with a chemical pneumonia. Extensive burning of the skin occurred. In the course of $10 \mathrm{yrs}$, lung function deteriorated progressively to a forced expiratory volume in one second of $30 \%$ of predicted value. Severe air-trapping occurred. The lung function abnormalities were not reversed by treatment with corticosteroids or bronchodilators. Infectious exacerbations of the child's lung disease occurred. High resolution computed tomography scan showed multiple bronchiectasis. The histological picture of an open lung biopsy was best described as a "chronic bronchiolitis".

Eur Respir J 2004; 23: 343-346.
*Dept of Paediatric Pulmonology, ${ }^{\text {\#}}$ Dept of Pathology and Dept of Pulmonology, University Hospital Maastricht, the Netherlands.

Correspondence: Edward Dompeling, University Hospital of Maastricht, PO Box 6202 AZ Maastricht, the Netherlands.

Fax: 31433875246

E-mail: edom@paed.azm.nl

Keywords: Bronchiolitis

poison gas

sulphur mustard gas

Received: October 312002

Accepted after revision: October 62003
Sulphur mustard (SM) gas is an alkylating agent which exerts a local action on the eyes, skin, and respiratory tissues with subsequent systemic action on the nervous, cardiac and digestive systems [1]. It was first used as a chemical weapon in World War I [2]. However, despite the Geneva accords, it has been used since that period on several occasions. Symptoms of the respiratory tract within $12 \mathrm{~h}$ of exposure may be sneezing, coughing, and loss of smell and taste, followed by laryngitis, aphonia, bronchitis and pneumonia within 36 to $48 \mathrm{~h}$ [1]. This study presents the long-term clinical history of a child exposed to SM gas at 5 yrs of age.

\section{Case report}

A previously healthy male child living in the Kurdish part of Iraq was exposed to an attack with SM gas in 1988 at 5 yrs of age. As a consequence of this attack, his whole family died. However, the boy survived. As an international refugee of the United Nations, he was sent to Brussels, Belgium, some days later for treatment in a hospital. The child's history prior to exposure was blank. He was born as a term infant, he had no serious pulmonary infections before the SM gas exposure. There were no indications for a disorder of his immune system. In a hospital in Brussels, he was treated for a chemical pneumonia and an infection with Haemophilus influenzae. During bronchoscopy, inflamed bronchial mucosa was found with hyperaemia and attenuated secretions. No inhalational particulates were detected in the bronchi. There were no indications for malacia or stenosis of the mainstem bronchi or trachea.

After 40 days, he returned back in relatively good condition to a little village close to the Iraq-Iran border where he lived together with his uncle. Between 1988 and 1992, a progressive worsening of his condition occurred with frequent infections (almost one every month) and an increase in dyspnoea and physical disability. At several occasions, he went to a hospital in Teheran, Iran, for treatment with antibiotics. The boy got asylum on political grounds in the Netherlands in 1992.

He presented in July 1992 in the Netherlands with multiple old skin burns with scars. The most important problem was his pulmonary status with serious coughing (especially at night) and dyspnoea. His exercise tolerance was diminished. He had a productive cough with yellow-green phlegm. Physical examination at the first visit in July 1992 revealed no dyspnoea at rest, but there was hyperinflation of the thorax and wheezing with a prolonged expirium and diffuse severe crackles all over the lungs. He had clubbing of the fingers. Chest radiography demonstrated a selective hyperinflation of the left lung with displacement of the mediastinum to the right side and numerous bullae at both sides. Ventilation-perfusion scintigraphy showed abnormalities with a perfusion left to right ratio of $62 / 38 \%$ and a ventilation ratio of $56 / 44 \%$. Especially the basal parts of the lungs had remarkably little vascularisation. Lung function testing showed severe airflow obstruction with air-trapping: forced expiratory volume in one second (FEV1) $0.76 \mathrm{~L}$ (45\% of predicted), forced vital capacity (FVC) of $1.47 \mathrm{~L}$ (71\% pred), inspiratory vital capacity $1.51 \mathrm{~L}(73 \%$ pred $)$, total lung capacity (TLC) $2.8 \mathrm{~L}$ (100\% pred), residual volume $1.39 \mathrm{~L}$ (199\% pred), airway resistance $1.77 \mathrm{kPa} \cdot \mathrm{L}^{-1} \cdot \mathrm{s}^{-1}$ (456\% pred). There was no bronchodilating response after administration of an inhaled $\beta_{2}$-agonist.

Treatment with corticosteroids (prednison $2 \mathrm{mg} \cdot \mathrm{kg}^{-1} \cdot \mathrm{day}^{-1}$ for 3 months) and bronchodilators ( $\beta_{2}$-agonists and ipratropium bromide) did not improve lung function or the clinical course of disease. Lung function deteriorated gradually in the course of 4 yrs to a FEV1 of $30 \%$ pred and a FVC of $40 \%$ pred. Infectious exacerbations of his lung disease occurred at several occasions and two hospital admissions in 1998 were 

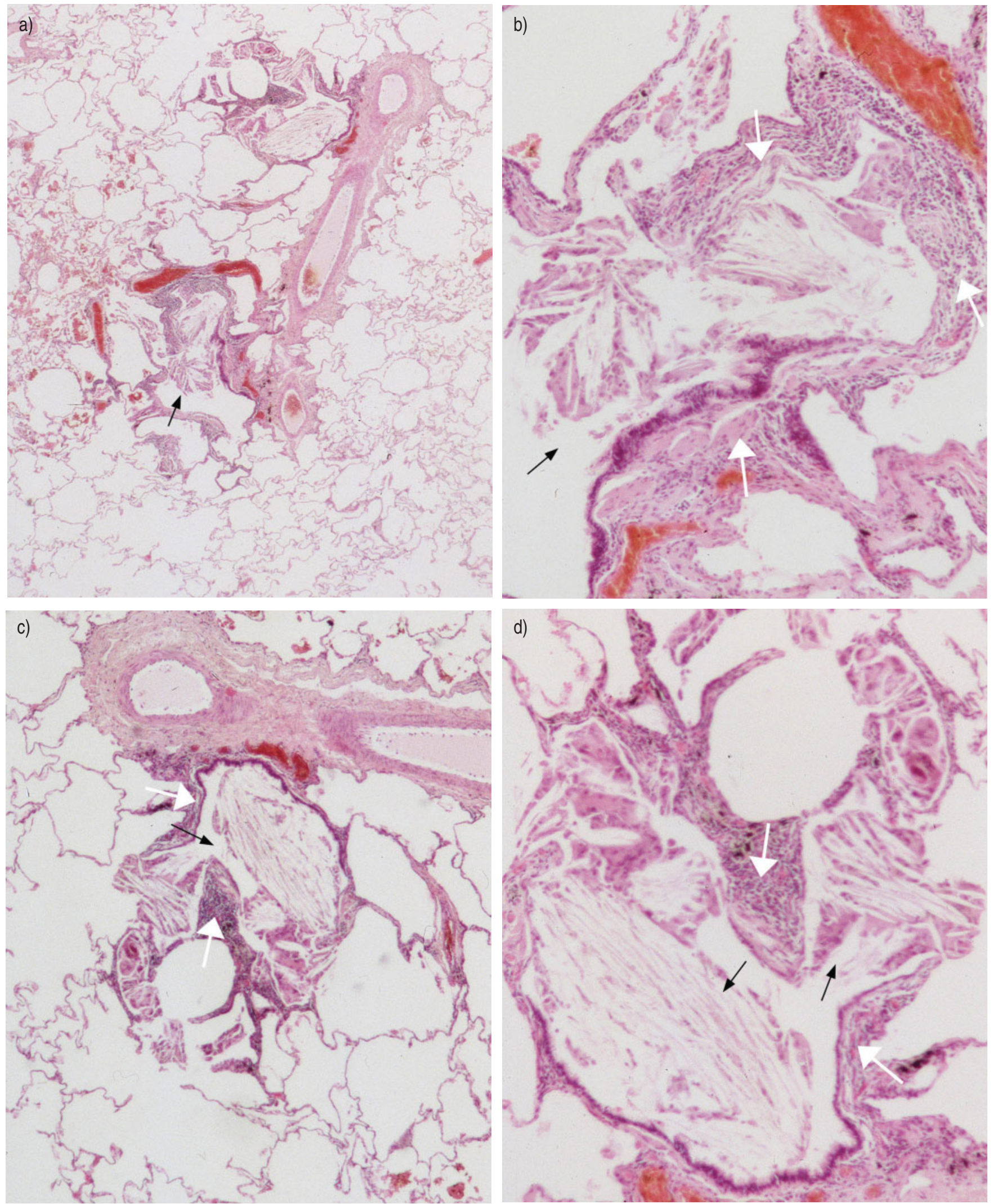

Fig. 1.-Histology of the lung biopsy in the case. a) Overview of the lung biopsy. This overview demonstrates dilatation of the bronchioli (i.e. bronchiectasis). The lumina of the bronchioli are filled with macrophages and histiocytic giant cells (black arrow); b-d) Closer view of these vascular bundles shows the same changes as described above (black arrows). Additionally, an inflammatory infiltrate in the wall of the bronchioli can be appreciated. This is mainly composed of mature, small lymphocytes and some plasma cells (white arrows). 
necessary for this reason. Cotrimoxazole prophylaxis was given. A diagnostic work-up for a lung transplantation was performed (November 1997). High resolution computed tomography of the thorax showed extensive bilateral bronchiectasis, most pronounced in the lower lobes. At least one bulla, situated paracardially, was filled with liquid. No stenosis of the main bronchi or trachea was observed. Continuous transcutaneous oxygen saturation measurements (without additional oxygen) showed values above $92 \%$ in rest and at night but immediate desaturation at exercise. In his sputum, H. influenzae and Streptococcus pneumoniae were cultured. No Pseudomonas was present. An open lung biopsy was performed (right upper lobe) in November 1997. Histology showed a "chronic bronchiolitis" with increased numbers of lymphocytes and plasma cells in the bronchiolar wall (fig. 1). The lumina of several bronchioli were filled with macrophages and multinucleated histiocytic giant cells. Interstitial or peribrochial fibrosis was not evident on lung biopsy.

The possibility of lung transplantation was discussed but the patient refused. In the course of time, FEV1 and FVC in litres remained more or less the same whereas TLC increased with growth (fig. 2). However, the FEV1\% pred value deteriorated progressively to $30 \%$ at $15 \mathrm{yrs}$ of age, but stabilised thereafter.

His height developed along the -1.5 SDS (standard deviation score) curve. His weight varied between the 0 and -1 SDS on the weight for height curve.

\section{Discussion}

This report describes severe long-term effects of SM gas exposure in a young child. Besides a chemical pneumonia in the acute phase, severe long-term damage to the lungs might occur in children after exposure to SM gas: bronchiolitis, bronchiectasis, progressive (irreversible) lung function abnormalities and severe impairment of physical activity. Lung function did not improve during treatment with bronchodilators or corticosteroids. Frequent infectious exacerbations occurred. Lung function (FEV1 and FVC as a \% pred value) deteriorated progressively after exposure to SM gas, but appeared to stabilise about 10 yrs after the original exposure. No data in the literature exist about exposure to SM gas in children.

Clinical description of males exposed to SM gas during World War I emphasised the initial effects on the respiratory

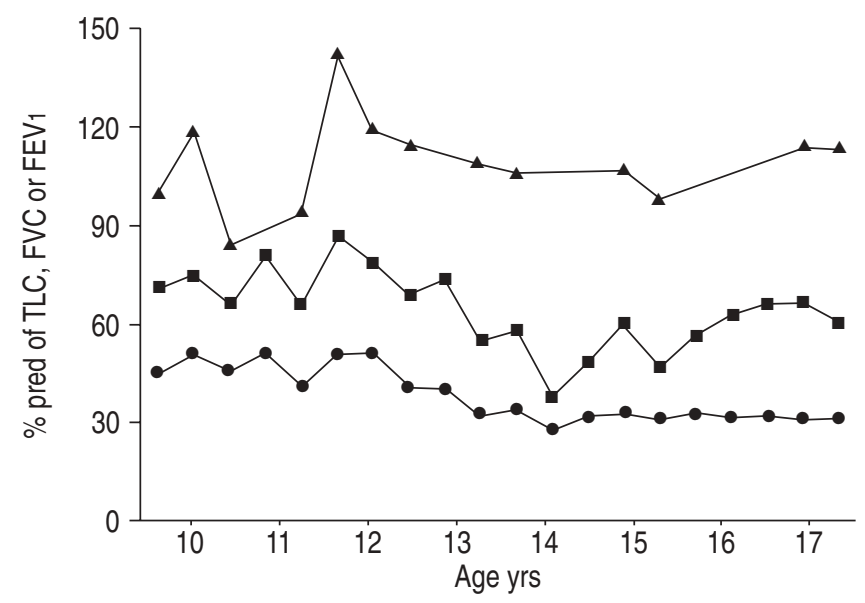

Fig. 2. - The course of the total lung capacity (TLC; $\mathbf{\Delta}$ ), forced vital capacity $(\mathrm{FVC} ; \mathbf{\square})$ and the forced expiratory volume in one second $\left(\mathrm{FEV}_{1} ; \boldsymbol{O}\right)$ in \% predicted values in the male child during age 9-18 yrs. system within $12 \mathrm{~h}$ : sneezing, coughing, irritation of mouth and throat, mucus discharge and loss of smell and taste. Longer periods of exposure to SM gas caused more severe symptoms as laryngitis, aphonia, bronchitis and pneumonia within 36 to $48 \mathrm{~h}[1,3-7]$. Diphteritic necrosis of the mucosa of the pharynx and larynx might occur 3-4 days after the exposure with dysphagia, difficulty in swallowing, rough voice or sometimes aphonia, burning sensations, painful paroxysmal coughing with sometimes a bloody and purulent expectoration. Hyperaemia, swelling and local necrosis in the larynx and trachea developed into whitish/greyish scars, which tended to form pseudomembranes. Healing of these lesions took several weeks. Severe intoxication (dependent of the dose and the length of the exposure to SM gas) might produce diphteritic lesions of the larynx, trachea, and bronchi, causing necrosis of the mucous membranes of the skin and the respiratory system with bronchitis, pneumonia, pulmonary congestion and oedema, leucopenia, convulsions with systemic distress, and even death [1, 3-5, 7]. The intoxication with SM could be confirmed by SM in urine, blood or faeces [1]. Treatment of SM intoxication is possible with sodium thiosulphate, cysteine, dexamethasone, methenamine, and vitamin $\mathrm{E}$ [1]. Thiosulphate in a dose of $500 \mathrm{mg} \cdot \mathrm{kg}^{-1} i . v$. within the first $20 \mathrm{~min}$ after the exposure to SM will avoid systemic intoxication and even lethal effects.

Recently, EMAD and REZAIAN [8] described late pulmonary sequelae of SM gas inhalation in Iranian veterans, $10 \mathrm{yr}$ after their single heavy SM gas exposure. Decreased lung function values, asthma, chronic bronchitis, bronchiectasis, airway narrowing through scarring, and pulmonary fibrosis were described [8].

Although other exposures than SM gas in the current case were not reported and also were not very likely, aspiration of foreign material cannot be completely excluded, or inhalation of particulates from, for instance, an explosion. However, bronchoscopy in the acute phase did not give an indication for an additional exposure.

The lung biopsy in the patient demonstrated a picture which can be best characterised as "chronic bronchiolitis". Several bronchioli were filled with macrophages and multinucleated giant cells. Typical Masson bodies (buds of granulation tissue), as present in BOOP (bronchiolitis obliterans and organising pneumonia), or narrowing of the bronchiolar lumen by concentric fibrosis (the hallmark of a constrictive bronchiolitis), were absent. A true bronchiolitis obliterans was not seen, however, the severity of this disease can be quite variable and cannot be completely excluded because of its absence in this biopsy (sampling effect).

In animal studies, inhalation of SM in mice demonstrated infiltration with inflammatory cells in the tracheobronchial epithelium already $6 \mathrm{~h}$ after exposure [9]. Inhalation exposure to SM induced a dose and time-dependent deoxyribonucleic acid (DNA) damage to the lungs of mice, with a typical "smear" form of cell death [10]. SM gas induced airway muscle hyperresponsiveness to substance $\mathrm{P}$ in guinea pigs, which might be inhibited by glucocorticoids [11]. Glutathione esters may protect the human upper respiratory tract cells against the SM damage [12].

The reason for stabilisation of the FEV1 (as \% pred) at 15 yrs of age is not completely clear. An explanation might be that his lungs did not grow with height because of irreversible damage of bronchiectasis, fibrosis, scarring or granulation tissue. Indeed, the FEV1 and FVC in litres remained more or less the same in the course of time. The exposure occurred in a critical period of lung growth [13]. An alternative explanation might be that SM gas is the trigger for an ongoing inflammatory reaction in the small airways with lymphocytes and macrophages, which is extinguished in the course of time.

Besides immediate effects, sulphur mustard gas can induce 
serious (long-term) pulmonary damage in children: chemical pneumoniae, progressive irreversible airway obstruction, bronchiolitis, bronchiectasis, and severe impairment of daily activities. The histological picture of a lung biopsy demonstrated a "chronic bronchiolitis".

\section{References}

1. Dacre JC, Goldman M. Toxicology and pharmacology of the chemical warfare agent sulfur mustard. Pharmacol Rev 1996; 48: 289-326.

2. Blanc PD. The legacy of war gas. Am J Med 1999; 106: 689690.

3. Warthin AS, Weller CV. The lesions of the respiratory and gastrointestinal tracts produced by mustard gas (dichloroethyl sulphide). J Lab Clin Med 1919; 4: 229-264.

4. Sollmann MT. A manual of pharmacology and its application to therapeutics and toxicology. 8th Edn. Philadelphia, WB Saunders Co., 1957.

5. Busher H. Green and yellow cross. Hamburg, R. Himmelheber and Co., 1931. Translated from the German by N. Conway, Kettering Laboratory of Applied Physiology, College of Medicine, University of Cincinnati, Cincinnati, $\mathrm{OH}$, pp. i-xi, 1-156, 1944.
6. Blewett WK. Tactical weapons: is mustard still king? Nuclear, Biological, Chemical Defense and Technology International 1986; 1: 64-66.

7. Haber L. The poisonous cloud. Oxford, Clarendon Press, 1986.

8. Emad A, Rezaian GR. The diversity of the effects of sulfur mustard gas inhalation on respiratory system 10 years after a single, heavy exposure. Chest 1997; 112: 734-738.

9. Pant SC, Vijayaraghavan R. Histomorphological and histochemical alterations following short-term exposure to sulfur mustard on visceral organs of mice. Biomed Environ Sci 1999; 12: 201-213.

10. Lakshmana Rao PV, Vijayaraghavan R, Bhaskar AS. Sulphur mustard induced DNA damage in mice after dermal and inhalation exposure. Toxicology 1999; 139: 39-51.

11. Calvet JH, D'Ortho MP, Jarreau PH, Levame M, Harf A, Macquin-Mavier I. Glucocorticoids inhibit sulfur mustardinduced airway muscle hyperreactivity to substance P. $J$ Appl Physiol 1994; 77: 2325-2332.

12. Andrew DJ, Lindsay CD. Protection of human upper respiratory tract cell lines against sulphur mustard toxicity by glutathione esters. Hum Exp Toxicol 1998; 17: 387-395.

13. Chernick V, Boat TF. Kendig's disorders of the respiratory tract in children. 6th Edn. Philadelphia, W.B. Saunders Company 1998, pp. 479-480. 